\title{
Sesamin attenuates allergic airway inflammation through the suppression of nuclear factor-kappa $B$ activation
}

\author{
LIANGCHANG LI $^{1 *}$, HONGMEI PIAO ${ }^{2 *}$, MINGYU ZHENG ${ }^{3}$, \\ ZHEWU JIN $^{1}$, LIGUANG ZHAO ${ }^{1}$ and GUANGHAI YAN ${ }^{1}$ \\ ${ }^{1}$ Department of Anatomy, Histology and Embryology, Yanbian University Medical College, Yanji, Jilin 133002; \\ ${ }^{2}$ Department of Respiratory Medicine, Yanbian University, Yanji, Jilin 133000; ${ }^{3}$ Department of Respiratory Medicine, \\ College of Pharmacy, Yanbian University, Yanji, Jilin 133002, P.R. China
}

Received July 29, 2015; Accepted October 5, 2016

DOI: $10.3892 /$ etm.2016.3903

\begin{abstract}
The aim of the present study is to determine the role of sesamin, the most abundant lignan in sesame seed oil, on the regulation of allergic airway inflammation in a murine asthma model. A BALB/c mouse model with allergic asthma was used to evaluate the effects of sesamin on nuclear factor-kappa B (NF- $\mathrm{B}$ ) activation. An enzyme-linked immunosorbent assay was used to determine protein expression in bronchoalveolar lavage (BAL) fluids. Hematoxylin and eosin staining was performed to examine histological changes. Moreover, western blot analysis was used to detect the expression of proteins in tissues. Prior to administering sesamin, the mice developed the following pathophysiological features of asthma: An increase in the number of inflammatory cells, increased levels of interleukin (IL)-4, IL-5 and IL-13, decreased levels of interferon- $\gamma$ in BAL fluids and lung tissues, increased immunoglobulin E ( $\mathrm{IgE}$ ) levels in the serum and an increased activation of $\mathrm{NF}-\kappa \mathrm{B}$ in lung tissues. Following treatment with sesamin, the mice had evidently reduced peribronchiolar inflammation and airway inflammatory cell recruitment, inhibited production of several cytokines in BAL fluids and lung tissues, and decreased IgE levels. Following inhalation of ovalbumin, the administration of sesamin also inhibited the activation of NF- $\mathrm{BB}$. In addition, sesamin administration reduced the phosphorylation of $\mathrm{p} 38$ mitogen-activated protein kinases (MAPKs). The present study demonstrates that sesamin decreases the activation of $N F-\kappa B$ in order to attenuate allergic airway inflammation in a murine model of asthma, possibly via the regulation of phosphorylation of p38
\end{abstract}

Correspondence to: Dr Guanghai Yan, Department of Anatomy, Histology and Embryology, Yanbian University Medical College, 977 Gongyuan Road, Yanji, Jilin 133002, P.R. China

E-mail: ghyan2015@sina.com

*Contributed equally

Key words: sesamin, asthma, nuclear factor-kappa B, airway inflammation, Th2 cytokine
MAPK. These observations provide an important molecular mechanism for the potential use of sesamin in preventing and/or treating asthma, as well as other airway inflammatory disorders.

\section{Introduction}

Asthma, one of the most frequent diseases worldwide, is a chronic inflammatory disease of the airways characterized by hyperresponsiveness, reversible airway obstruction and airway inflammation (1). The pathological features of allergic asthma include edema, inflammatory cell infiltration, denudation of the airway epithelium, mast cell activation and collagen deposition (2). Moreover, asthma is associated with an imbalance of $\mathrm{T}$ helper $(\mathrm{Th}) 1 / \mathrm{Th} 2$ cells and their different cytokine profiles $(3,4)$. Th2-specific cytokines, including interleukin (IL)-4, 5 and 13, are important in the mediation of humoral immune responses and immunoglobulin E ( $\mathrm{IgE}$ ) production by affecting eosinophils in the airway. Furthermore, the release of Th2 cytokines, including histamine and leukotriene, is associated with hyperresponsiveness $(5,6)$. Th1 cytokines, including interferon (IFN) $-\gamma$ and IL-12, mediate cellular immune reactions, the antagonism of Th2 immune responses, and $\operatorname{IgE}$ synthesis in order to restrain asthma development (7). If the dynamic balance of Th1/Th2 cells is disturbed, the subject is more likely to experience a disease (8). Therefore, researchers have examined ways of inhibiting the activation of Th2 cells or the modulation of the Th1/Th2 balance as a way of preventing and treating asthma (9).

Nuclear factor-kappa B $(\mathrm{NF}-\kappa \mathrm{B})$, a well-studied transcriptional factor that is important in signaling pathways, is also important in airway remodeling in asthma $(10,11)$. Cytokines and other factors triggered as part of inflammatory processes activate $\mathrm{NF}-\kappa \mathrm{B}$ via several signaling pathways, leading to a signaling cascade that amplifies inflammation (10). Several studies associate $\mathrm{NF}-\kappa \mathrm{B}$ overactivation with airway remodeling $(12,13)$. The p38 mitogen-activated protein kinases (MAPKs) represent a point of convergence for multiple signaling processes that are activated in inflammation, as well as a diverse range of events that are important in inflammation $(14,15)$. Various proinflammatory transcription factors, 
including activator protein 1 (AP-1) and NF- $\mathrm{\kappa B}(16-18)$ are regulated by the $\mathrm{p} 38$ MAPK pathway.

Lignans from Sesamum indicum L. seeds are potent antioxidants. Sesamin, a type of lignan, is the most abundant in sesame seed oil (19). Previous studies reveal that sesamin reduces the frequency of chemically-induced mammary tumors, enhances hepatic detoxification and protects against oxidative stress $(20,21)$. Moreover, previous studies indicate that sesamin has other potential pathways for bioactivity, including the inhibition of delta-5 desaturase activity in the fatty acid metabolism, which results in the accumulation of dihomo- $\gamma$-linolenic acid. Dihomo- $\gamma$-linolenic acid is capable of displacing arachidonic acid and decreasing the formation of proinflammatory mediators, such as prostaglandin E2 and leukotriene B4 $(22,23)$. Moreover, another study of ours demonstrated that sesamin inhibits lipopolysaccharide-induced IL-6 production by suppressing NF- $\mathrm{KB}$ and $\mathrm{p} 38$ MAPK activation (24). Sesamin also partially reverses IL-1 $\beta$ signaling in human astrocyte-cerebellar cultures, leading to the inhibition of matrix metallopeptidase-1, -3 and -13 expression (25). The study further demonstrated that this inhibition occurred through the p38 and c-Jun N-terminal kinase signaling pathways, but not through extracellular regulated protein kinases $1 / 2(25)$. The present study examines the anti-inflammatory mechanism of sesamin in a mouse asthma model.

\section{Materials and methods}

Animals. A total of 35 specific pathogen-free inbred female BALB/c mice (age, 7 weeks) were purchased from Yanbian University Health Science Center (Yanji, China). The mice were kept in an animal facility under standard laboratory conditions for 1 week prior to the experiments, with water and standard food ad libitum. All animal experiments were conducted according to the guidelines approved by the Institutional Animal Care and Use Committee of Yanbian University School of Medical Sciences (Yanji, China).

The mice were intraperitoneally immunized with $10 \mu \mathrm{g}$ chicken egg ovalbumin (OVA; Sigma-Aldrich; Merck KGaA, Darmstadt, Germany) and $1.0 \mathrm{mg}$ aluminum hydroxide adjuvant (Imject Alum; Pierce Protein Biology; Thermo Fisher Scientific, Inc., Rockford, IL, USA). The mice received a booster injection with $10 \mu \mathrm{g}$ OVA and $1.0 \mathrm{mg}$ aluminum hydroxide adjuvant 10 days later. In addition, between days 17 and 19, the immunized mice were exposed to a $1 \%$ OVA aerosol in phosphate-buffered saline (PBS) for $20 \mathrm{~min}$. The bronchoprovocation procedure was performed in vented plastic chambers $(18 \times 14 \times 8 \mathrm{~cm})$ that were adapted for mice. Aerosol particles of 3-5 $\mu \mathrm{m}$ diameter were created using an ultrasonic nebulizer (NE-U12; Omron Corporation, Kyoto, Japan), then vented into a fume hood. Each test group consisted of seven mice. Mice in the control group were treated with aerosol of saline. Sesamin dissolved in vehicle composed of $0.5 \%(w / v)$ carboxy methylcellulose and $0.025 \%$ Tween 20 in distilled water (200 mg/kg body weight; Sigma-Aldrich), or the reference drug dexamethasone (DXM; $0.5 \mathrm{mg} / \mathrm{kg}$ body weight; Sigma-Aldrich) was administered by oral gavage to each animal at 24-h intervals on days 17-19, beginning $1 \mathrm{~h}$ before the first provocation.
Immediately after the assessment of airway responsiveness, the mice were anesthetized by intraperitoneal injection of pentobarbital $(50 \mathrm{mg} / \mathrm{kg}$; Wuhan Boster Biological Technology, Ltd., Wuhan, China), and their tracheas cannulated while gently massaging their thoraxes. Moreover, the lungs were lavaged with $0.7 \mathrm{ml}$ PBS. Bronchoalveolar lavage (BAL) fluid samples were collected and the number of total cells in a $0.05-\mathrm{ml}$ aliquot were counted using a hemocytometer. The remaining samples were centrifuged at $1,200 \times \mathrm{g}$ for $10 \mathrm{~min}$ at $4^{\circ} \mathrm{C}$ (model 5424R; Eppendorf Instrumente $\mathrm{GmbH}$, Hamburg, Germany), and the supernatants stored at $-70^{\circ} \mathrm{C}$ before use. Cell pellets were resuspended in PBS and cytospin (Cytospin 3; Shandon Scientific Limited, Astmoor, UK) preparations of BAL cells were stained with Diff-Quik solution (International Reagents Corporation, Kobe, Japan). A total of two independent, double-blinded investigators counted the cells using a microscope (CX41; Olympus Corporation, Tokyo, Japan). In total, 400 cells were counted in each of four different random locations. The inter-investigator variation was $<5 \%$, and the mean number from the two investigators was used to estimate cell differentials.

Enzyme-linked immunosorbent assay (ELISA). IL-4 (M4000B), IL-5 (M5000), IL-13 (M1300CB) and IFN- $\gamma$ (MIF00) levels in BAL were determined using mouse ELISA kits (R\&D Systems, Inc., Minneapolis, MN, USA) according to the manufacturer's instructions. The sensitivity was $2.0 \mathrm{pg} / \mathrm{ml}$ for IL-4, IL-5, IL-13 and IFN- $\gamma$.

Hematoxylin and eosin (HE) staining. Following BAL, murine lungs were resected, fixed with $4 \%$ paraformaldehyde and embedded in paraffin. Specimens were cut into 4- $\mu \mathrm{m}$ sections using a rotary microtome (2165; Leica Biosystems Nussloch Gmbh, Nussloch, Germany), and the microsections were stained with HE (Richard-Allan Scientific, Kalamazoo, MI, USA). Furthermore, they were examined under a magnification of $\mathrm{x} 100$.

Nuclear protein extraction. Freshly isolated lung tissues were washed and lysed in 2 volumes of lysis buffer A containing $50 \mathrm{mM}$ Tris- $\mathrm{HCl}, \mathrm{pH} 7.5,1 \mathrm{mM}$ EDTA, $10 \%$ glycerol, $0.5 \mathrm{mM}$ dithiothreitol, $5 \mathrm{mM} \mathrm{MgCl}{ }_{2}, 1 \mathrm{mM}$ phenylmethylsulfonyl fluoride (PMSF) and protease inhibitor cocktails for $5 \mathrm{~min}$ at $4^{\circ} \mathrm{C}$ (all lysis buffer reagents purchased from Sigma-Aldrich). The suspension was centrifuged at $1,000 \mathrm{x} g$ for $15 \mathrm{~min}$ at $4^{\circ} \mathrm{C}$. Cytosolic proteins were extracted from the supernatant by incubating on ice for $10 \mathrm{~min}$ and centrifuging at $100,000 \mathrm{x} g$ for $1 \mathrm{~h}$ at $4^{\circ} \mathrm{C}$. The pelleted nuclei were resuspended in buffer $\mathrm{B}$ containing $1.3 \mathrm{M}$ sucrose, $1.0 \mathrm{mM} \mathrm{MgCl}$ and $10 \mathrm{mM}$ potassium phosphate buffer ( $\mathrm{pH}$ 6.8), and centrifuged at 1,000 x $g$ for $15 \mathrm{~min}$. The pellets were suspended in buffer $\mathrm{B}$ to a final sucrose concentration of $2.2 \mathrm{M}$ and centrifuged at $100,000 \mathrm{x} g$ for $1 \mathrm{~h}$. The nuclear pellets were washed once with a solution containing $0.25 \mathrm{M}$ sucrose, $0.5 \mathrm{mM} \mathrm{MgCl}_{2}$ and $20 \mathrm{mM}$ Tris- $\mathrm{HCl}(\mathrm{pH}$ 7.2), and centrifuged again at $1,000 \times \mathrm{g}$ for $10 \mathrm{~min}$. The new pellets were then solubilized with a solution containing $50 \mathrm{mM}$ Tris- $\mathrm{HCl}(\mathrm{pH} 7.2), 0.3 \mathrm{M}$ sucrose, $150 \mathrm{mM} \mathrm{NaCl}, 2 \mathrm{mM}$ EDTA, 20\% glycerol, 2\% Triton X-100, $2 \mathrm{mM}$ PMSF and protease inhibitor cocktails. Furthermore, the mixture was kept on ice for $1 \mathrm{~h}$ with gentle stirring and 
centrifuged at $12,000 \times \mathrm{g}$ for $30 \mathrm{~min}$. The resulting supernatant was used as the soluble nuclear protein sample for western blot analysis.

Western blot analysis. Lung tissue samples were homogenized and lysed in two volumes of lysis buffer containing $50 \mathrm{mM}$ Tris- $\mathrm{HCl}(\mathrm{pH} 7.5), 150 \mathrm{mM} \mathrm{NaCl}, 1 \%$ Nonidet-P40, $1 \%$ sodium deoxycholate, $0.1 \mathrm{mM}$ dithiothreitol, $0.5 \mathrm{mM}$ EDTA, $1 \mathrm{mM}$ sodium vanadate, $2 \mathrm{mM}$ phenylmethylsulfonyl fluoride, $1 \mu \mathrm{g} / \mathrm{ml}$ aprotinin, $1 \mu \mathrm{g} / \mathrm{ml}$ leupeptin and $1 \mu \mathrm{g} / \mathrm{ml}$ pepstatin. The mixture was kept on ice for $1 \mathrm{~h}$ with gentle vortexing and centrifuged at $8,000 \times \mathrm{g}$ for $15 \mathrm{~min}$. The resulting supernatant was stored at $-80^{\circ} \mathrm{C}$ (total extracts). Protein samples $(30 \mu \mathrm{g})$ from the lung homogenates were separated using $12 \%$ SDS-PAGE, and the proteins were then transferred onto a nitrocellulose membranes. Nonspecific sites were blocked with 5\% non-fat dry milk in TBST buffer [25 mM Tris (pH 7.5), $150 \mathrm{mM} \mathrm{NaCl}, 0.1 \%$ Tween 20] for $1 \mathrm{~h}$, and washed with TBST for four times of $10 \mathrm{~min}$. Western blot analysis was performed using polyclonal antibodies against IL-5 (sc-7887; 1:1,000), p38, phosphorylated p38 (p-p38; sc-535; $1: 1,000)$, poly ADP ribose polymerase (sc-25780; $1: 1,000$ ), NF-кB p65 (sc-109; 1:1,000), IкB- $\alpha$ (sc-847; 1:1,000), $\beta$-actin (sc-130656; 1:1,000; Santa Cruz Biotechnology, Inc., Santa Cruz, CA, USA), IL-13 (AF-413-NA; 1:1,000; R\&D Systems, Inc.), IFN- $\gamma$ (sc-9344; 1:1,000; Santa Cruz Biotechnology, Inc.) or IL-4 (AAM36; 1:1,000; Bio-Rad Laboratories, Inc.). Membranes were probed with primary antibody $(1: 1,000)$ overnight on a shaker at $4^{\circ} \mathrm{C}$. After washing with TBST for four times of $10 \mathrm{~min}$, membranes were incubated with secondary antibody $(1: 2,500)$ for $2 \mathrm{~h}$. Binding of the antibodies was detected using an enhanced chemiluminescence detection system (Amersham Life Science, Arlington Heights, IL, USA) according to the manufacturer's instructions. The band intensity was quantified using Quantity One software (Bio-Rad Laboratories, Inc.). All experiments were repeated for at least three times.

Statistical analysis. All immunoreactive and phosphorylation signals were analyzed by densitometric scanning (Gel Doc XR; Bio-Rad Laboratories, Inc.). The results were analyzed using SPSS 17.0 (SPSS, Inc., Chicago, IL, USA). The data were expressed as the mean \pm standard error of the mean. Statistical evaluation of the data was performed using analysis of variance followed by Dunnett's post-hoc test. $\mathrm{P}<0.05$ was used to indicate a statistically significant difference.

\section{Results}

Sesamin reduces the number of cells in BAL fluids of OVA-induced asthma. In order to examine the effect of sesamin on cellular changes in BAL fluids of OVA-induced asthma, the number of various cells were counted. The data revealed that the numbers lymphocytes, eosinophils and neutrophils in BAL fluids were significantly increased at $48 \mathrm{~h}$ after OVA inhalation compared with those following saline inhalation (Fig. 1). In addition, administration of sesamin or DXM significantly reduced the number of these cells. These results indicate that sesamin reduces the number of cells in BAL fluids of OVA-induced asthma.

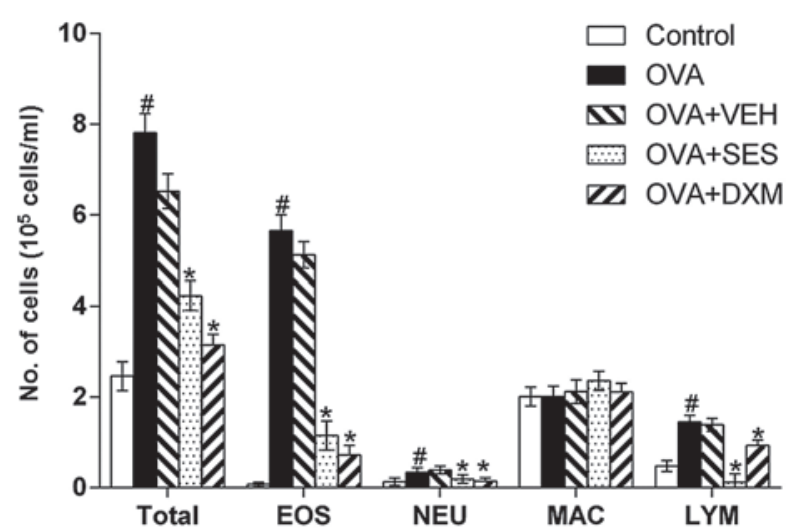

Figure 1. Effect of sesamin on total and differential cellular components of bronchoalveolar lavage in OVA-challenged mice. The numbers of cells from five independent experiments with seven mice per group are given as means \pm standard error of the mean. ${ }^{\#} \mathrm{P}<0.05$ vs. control group; ${ }^{*} \mathrm{P}<0.05$ vs. OVA group. OVA, ovalbumin; EOS, eosinophil; NEU, neutrophil; MAC, macrophage; LYM, lymphocyte, VEH, vehicle composed of $0.5 \%$ (w/v) carboxy methylcellulose and $0.025 \%$ Tween 20 in distilled water; SES, sesamin; DXM, dexamethasone.

Sesamin inhibits the infiltration of inflammatory cells and attenuates antigen-induced airway inflammation. In order to study the effect of sesamin on the pathological changes of OVA-induced asthma, histological examinations were undertaken. The examinations revealed typical pathological features of asthma in OVA-challenged mice through widespread perivascular and peribronchiolar inflammatory cell infiltrates, as compared to the control. Moreover, the mice treated with sesamin or DXM demonstrated significantly reduced inflammatory cell infiltration in the peribronchiolar and perivascular regions, compared with the OVA group (Fig. 2). These results indicate that sesamin attenuates antigen-induced airway inflammation and inhibits the infiltration of inflammatory cells.

Treatment with sesamin suppresses the increase in $I L-4, I L-5$ and IL-13 levels. Western blot analysis and ELISA were used to investigate the effect of sesamin on IL-4, IL-5 and IL-13 protein levels in lung tissues and in BAL fluids of OVA-induced asthma, respectively. Western blotting demonstrated that IL-4, IL-5 and IL-13 protein levels in lung tissues were significantly increased $48 \mathrm{~h}$ after OVA inhalation compared with the levels following saline inhalation. Moreover, the increased IL-4, IL-5 and IL-13 levels were significantly reduced by the administration of sesamin or DXM (Fig. 3A). Consistent with these results, ELISA revealed that the levels of IL-4, IL-5 and IL-13 in BAL fluids were also significantly increased at $48 \mathrm{~h}$ after OVA inhalation compared with the control group (Fig. 3B). These results indicate that treatment with sesamin suppresses the increase in the IL-4, IL-5 and IL-13 levels.

Treatment with sesamin increases the decreased IFN- $\gamma$ level in allergic mice. In order to determine the effect of sesamin on the Th1 response, IFN- $\gamma$ levels in lung tissues and BAL fluids were measured using western blotting and ELISA, respectively. The IFN- $\gamma$ level in OVA-challenged mice was lower than that in the control mice (Fig. 4A). However, administration of DXM or sesamin increased the levels of IFN- $\gamma$ in 

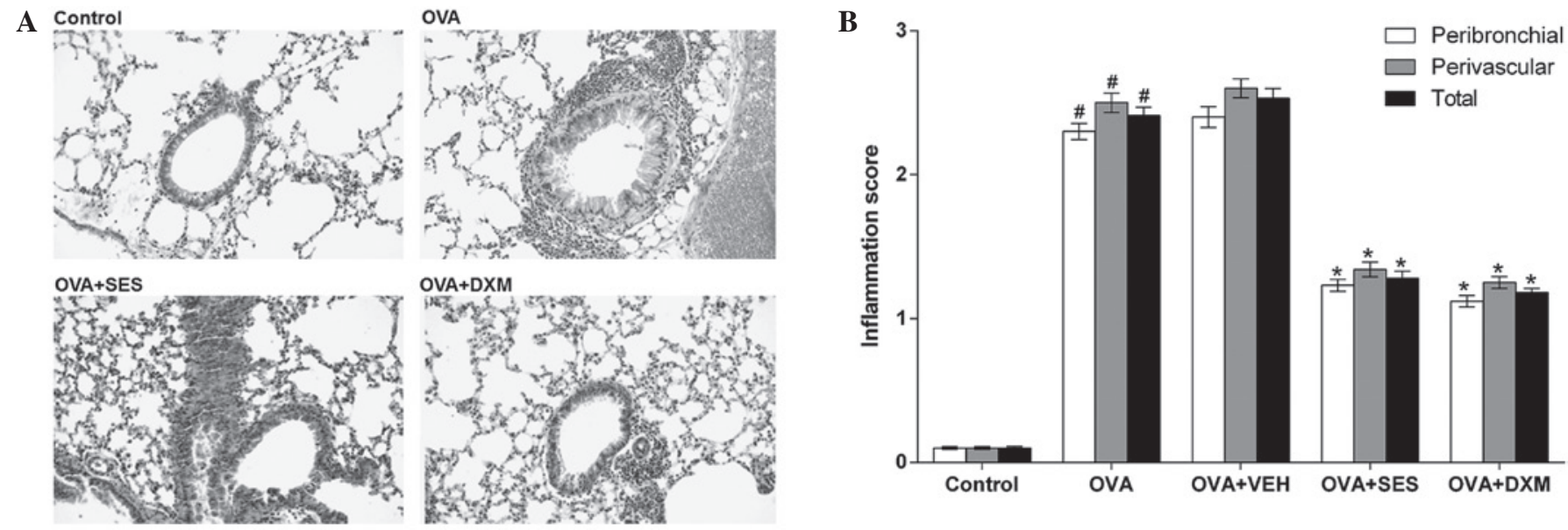

Figure 2. Effect of sesamin on pathologic changes in lung tissues in OVA-challenged mice. (A) Paraffin-embedded lung sections prepared $48 \mathrm{~h}$ after the last OVA challenge and stained with hematoxylin and eosin (magnification, x200). (B) Scores of peribronchial, perivascular and total lung inflammation. Data from five independent experiments with seven mice per group are given as means \pm standard error of the mean. ${ }^{*} \mathrm{P}<0.05 \mathrm{vs}$. control; " $\mathrm{P}<0.05 \mathrm{vs}$. OVA. OVA, ovalbumin; VEH, vehicle composed of $0.5 \%$ (w/v) carboxy methylcellulose and $0.025 \%$ Tween 20 in distilled water; SES, sesamin; DXM, dexamethasone.

A
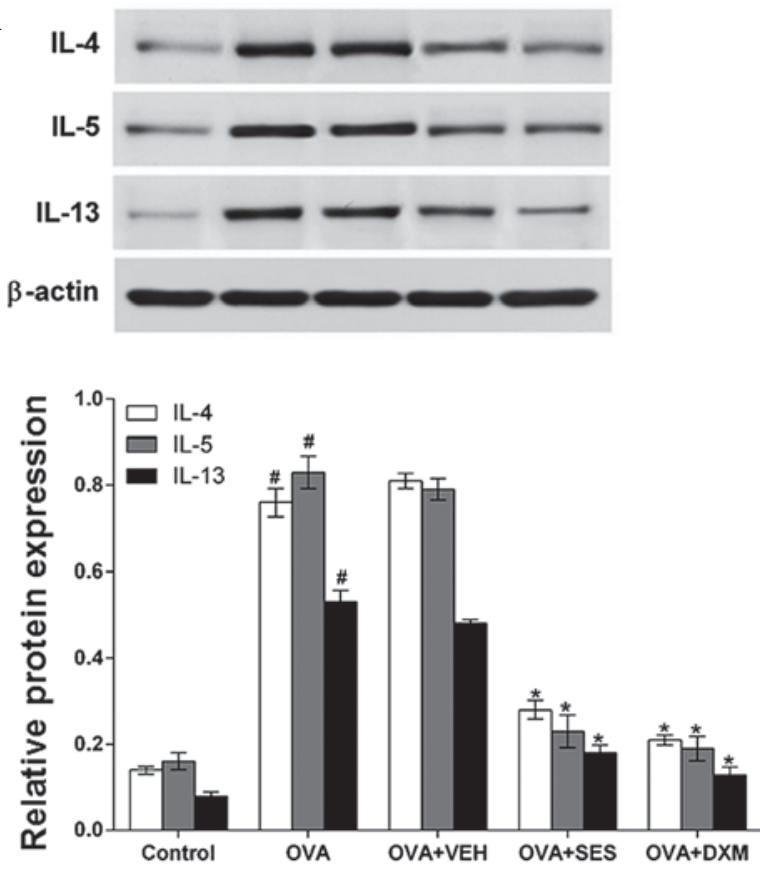

B

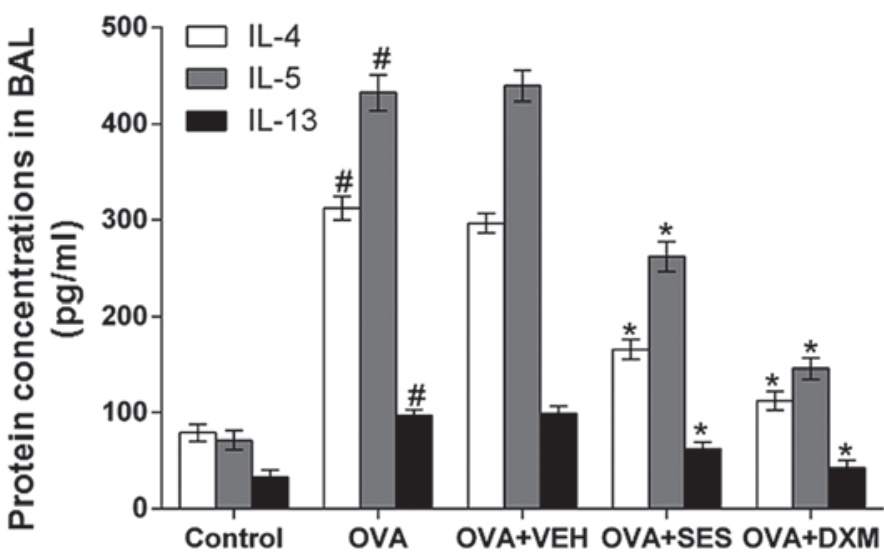

Figure 3. Assessment of Th2 cytokines in bronchoalveolar lavage fluids and lung tissues of OVA-sensitized mice treated with sesamin. (A) Protein expressions of IL-4, IL-5 and IL-13 in lung tissues after $48 \mathrm{~h}$ measured by western blotting. Density ratio against $\beta$-actin was measured using a densitometer. (B) Levels of these cytokines quantified by specific ELISA assay kits. Data from five independent experiments with seven mice per group are given as the means \pm standard error of the mean. ${ }^{~} \mathrm{P}<0.05$ vs. control; ${ }^{\mathrm{P}}<0.05$ vs. OVA. IL, interleukin; OVA, ovalbumin; VEH, vehicle composed of $0.5 \%$ (w/v) carboxy methylcellulose and $0.025 \%$ Tween 20 in distilled water; SES, sesamin; DXM, dexamethasone; BAL, bronchoalveolar lavage.

OVA-challenged mice. In agreement with this result, western blotting demonstrated that the IFN- $\gamma$ protein level in the lung tissue was significantly decreased in allergic mice compared with that in the control mice (Fig. 4B). It is noteworthy that the decreased IFN- $\gamma$ level was increased after pretreatment with sesamin or DXM. These results indicate that treatment with sesamin increases the decreased IFN- $\gamma$ level in the lung tissue of allergic mice.

Sesamin prevents the translocation of $N F-\kappa B$ by blocking phosphorylation and degradation of I $\kappa B-\alpha$ in $O V A$-challenged mice. Western blotting was used to determine the effect of sesamin on $\mathrm{NF}-\kappa \mathrm{B}$ p 65 and phosphorylation levels of I $\kappa \mathrm{B}-\alpha$ protein in the lung tissues of mice with OVA-induced asthma. The data demonstrated that the levels of NF- $\kappa \mathrm{B}$ p65 in nuclear protein extracts from lung tissues were increased at $48 \mathrm{~h}$ after OVA was inhaled compared with the levels in mice used as the control. The increased NF- $\kappa$ B p65 levels at $48 \mathrm{~h}$ after OVA inhalation were decreased after sesamin or DXM was administered. By contrast, the levels of $\mathrm{NF}-\kappa \mathrm{B}$ p65 in cytosolic protein extracts from lung tissues were decreased at $48 \mathrm{~h}$ after OVA inhalation in comparison to 
A

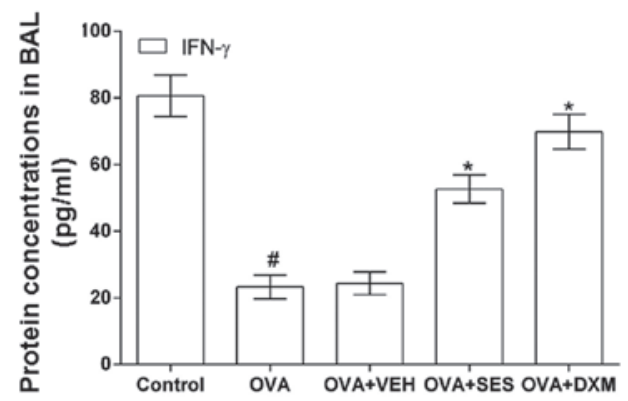

B
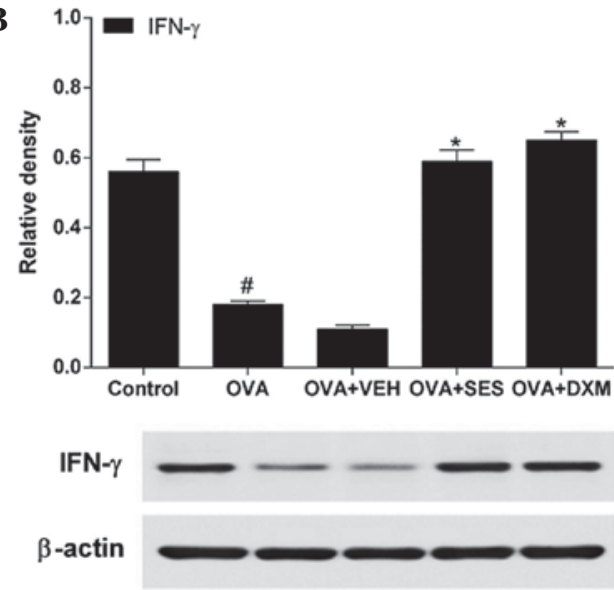

Figure 4. Assessment of Th1 cytokines in bronchoalveolar lavage fluids and lung tissues of OVA-sensitized mice treated with sesamin. (A) Levels of IFN- $\gamma$ quantified by specific ELISA kits. (B) Protein expressions of these cytokines in lung tissues after $48 \mathrm{~h}$ measured by western blotting. Density ratio against $\beta$-actin was measured using a densitometer. Data from five independent experiments with seven mice per group are given as means \pm standard error of the mean. ${ }^{*} \mathrm{P}<0.05$ vs. control; "P<0.05 vs. OVA. OVA, ovalbumin; VEH, vehicle composed of $0.5 \%$ (w/v) carboxy methylcellulose and $0.025 \%$ Tween 20 in distilled water; SES, sesamin; DXM, dexamethasone; IFN, interferon.

A
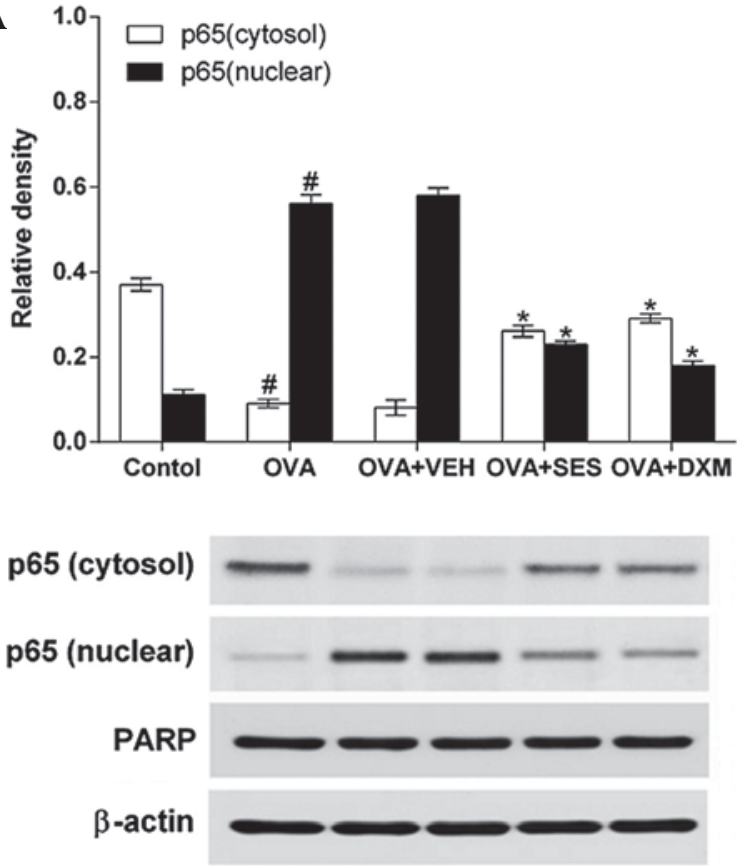

B
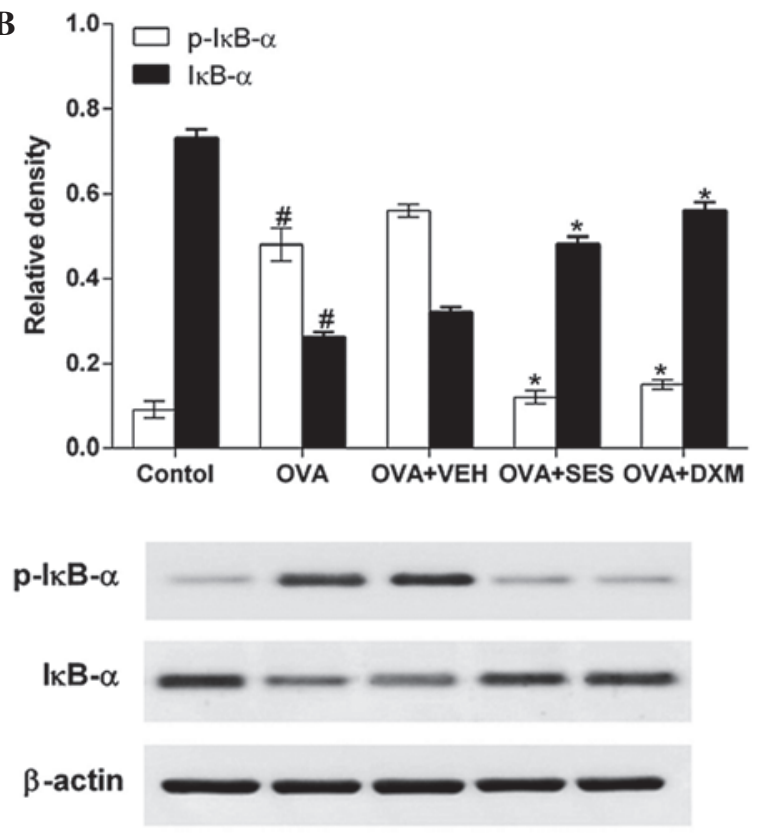

Figure 5. Effect of sesamin on OVA challenge-induced nuclear factor- $\kappa \mathrm{B}$ activation determined by western blotting. (A) Translocation of p65 to the nucleus. (B) I $\mathrm{B}-\alpha$ phosphorylation and degradation in cytoplasm. We used $\beta$-actin and PARP as internal controls. A representative immunoblot of five independent experiments is shown. Density ratio against $\beta$-actin or PARP was measured using a densitometer. Data from five independent experiments with seven mice per group are given as the mean \pm standard error of the mean. ${ }^{~} \mathrm{P}<0.05$ vs. control; ${ }^{*} \mathrm{P}<0.05$ vs. OVA. PARP, poly ADP ribose polymerase; OVA, ovalbumin; VEH, vehicle composed of $0.5 \%$ (w/v) carboxy methylcellulose and $0.025 \%$ Tween 20 in distilled water; SES, sesamin; DXM, dexamethasone.

the control (Fig. 5A). The decreased NF- $\kappa \mathrm{B}$ p65 levels in the cytosolic preparations were increased after sesamin or DXM was administered. Moreover, the effect of sesamin on degradation of I $\kappa \mathrm{B}-\alpha$ and on OVA-induced phosphorylation was studied in order to investigate the molecular mechanisms by which sesamin inhibits $\mathrm{NF}-\kappa \mathrm{B}$ transcriptional activity. Sesamin was observed to significantly block OVA-induced phosphorylation and degradation of IкB- $\alpha$ (Fig. 5B). These results indicate that sesamin prevents $N F-\kappa B$ translocation by blocking the phosphorylation and degradation of $I \kappa B-\alpha$ in OVA-challenged mice.
Treatment with sesamin reduces the phosphorylation levels of 38 MAPK protein in lung tissue of mice with OVA-induced asthma. In order to test the effect of sesamin on the phosphorylation levels of p38 MAPK protein in the lung tissue of mice with OVA-induced asthma, western blotting was used to determine the activation of p38 MAPK, which is an upstream signaling mediator of $N F-\kappa B$. The data revealed that the levels of p-p38 protein in lung tissues were increased at $48 \mathrm{~h}$ after OVA inhalation compared with the levels in the control mice (Fig. 6). However, no significant changes were observed in the 338 protein levels in any of the groups tested. 


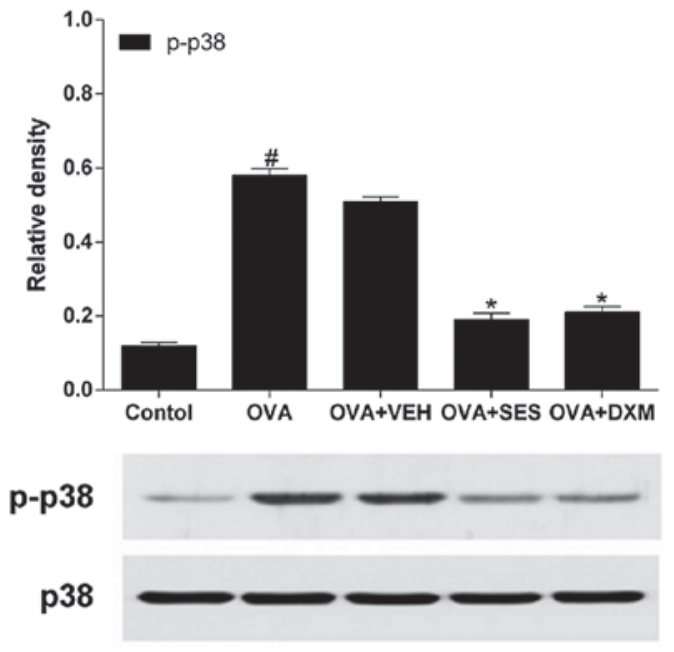

Figure 6. Effect of sesamin on OVA challenge-induced p38 activation. Phosphorylated p38 was assessed by western blotting. Total p38 was used as internal controls. Density ratio against total p38 was measured using a densitometer. Data from five independent experiments with seven mice per group are given as the means \pm standard error of the mean. ${ }^{\#} \mathrm{P}<0.05$ vs. control; " $\mathrm{P}<0.05$ vs. OVA. OVA, ovalbumin; VEH, vehicle composed of $0.5 \%$ (w/v) carboxy methylcellulose and $0.025 \%$ Tween 20 in distilled water; SES, sesamin; DXM, dexamethasone.

The administration of sesamin or DMX significantly reduced the levels of p-p38 at Thr 180 and Tyr 182 (but not the total p38 protein levels) in lung tissues at $48 \mathrm{~h}$ after OVA inhalation. This result indicates that treatment with sesamin reduces the phosphorylation levels of the p38 MAPK protein in the lung tissue of mice with OVA-induced asthma.

\section{Discussion}

Allergic asthma is a chronic inflammatory illness of the airways characterized by airway inflammatory cell infiltration and hyperresponsiveness to inhaled allergens and nonspecific stimuli (26). Inflammatory cells, including Th2, mast cells, macrophages, lymphocytes, eosinophils and neutrophils, as well as the release of cytokines (particularly IL-4, IL-5 and IL-13) are important in asthma $(27,28)$. The results of the present study reveal that sesamin reverses or prevents some of these effects in mice suffering from asthmatic symptoms. The number of total cells, eosinophils, neutrophils and lymphocytes in BAL fluid were much lower in OVA-induced mice treated with sesamin compared to those in the control group. The expression of Th2 cytokines, including IL-4, IL-5 and IL-13 was increased, and the expression of Th1 cytokines such as IFN- $\gamma$ was decreased during the induction of asthma. Sesamin significantly reduced OVA-induced enhancement of IL-4, IL-5 and IL-13 expression, and increased OVA-induced attenuation of IFN- $\gamma$ expression in lung tissues and BAL fluids. Consistent with these biochemical observations, HE staining revealed that sesamin treatments improved airway inflammation.

Airway inflammation is connected by complex signaling networks. As a result, we still do not fully understand the molecular mechanisms of this disorder. NF- $\mathrm{B}$ is present in the majority of cell types and is known to be important in immune and inflammatory responses, including asthma (29-32). In unstimulated cells, I $\kappa \mathrm{B} \alpha$ proteins sequester $\mathrm{NF}-\kappa \mathrm{B}$ into the cytoplasm. However, phosphorylation and degradation of $\mathrm{IkB} \alpha$ allows the translocation of $\mathrm{NF}-\kappa \mathrm{B}$ into the nucleus where it regulates transcription of target genes, which encode numerous inflammatory proteins (33) such as cytokines IL-4, IL-5 and IL-13, all of which are closely implicated in the pathogenesis of asthma (34). It is consistent with the observations of the present study that $\mathrm{NF}-\kappa \mathrm{B}$ levels in nuclear protein extracts from lung tissues are substantially increased in the OVA-induced model of allergic airway disease. Sesamin significantly reduced the degradation of $\mathrm{I} \kappa \mathrm{B} \alpha$, the translocation of the p65 subunit of NF- $\mathrm{BB}$ into the nucleus, and the levels of Th2 cytokines (IL-4, IL-5 and IL-13) in the lungs of OVA-induced mice. These results suggest that sesamin alleviates asthmatic symptoms through the modulation of $\mathrm{NF}-\kappa \mathrm{B}$ activation.

MAPKs belong to the serine/threonine kinase family that includes extracellular signal-regulated kinases, c-Jun $\mathrm{N}$-terminal kinases (JNK) and p38MAPK.MAPKs relay signals generated by endogenous and exogenous stimuli to the intracellular space through the phosphorylation of proteins (35-37). The activities and/or phosphorylation states of all three MAPK members are upregulated in asthma animal models $(38,39)$. In addition, a potent and selective p38 MAPK inhibitor named SB239063 promotes the apoptosis of eosinophils in BAL fluid and significantly inhibits antigen-induced eosinophilia (40). In addition, p38 MAPK inhibitors reduce levels of IL-4, IL-5 and IL-13, mucus hypersecretion, antigen-induced airway inflammatory cell infiltration and airway hyperresponsiveness (41). Furthermore, sesamin inhibits IL-1 $\beta$-induced phosphorylation of JNK and p38 MAPK in human articular chondrocytes (25). Consistent with this data, the present study reveals that phosphorylation of p38 MAPK is evidently increased following OVA inhalation, and that sesamin significantly decreases the levels of p-p38 MAPK in lung tissues of OVA-inhaled mice. In addition, it was revealed that sesamin does not only reduce allergen-induced airway inflammation, but also interrupts the translocation of the p 65 subunit of NF- $\kappa \mathrm{B}$ and degrades I $\kappa \mathrm{B} \alpha$. These observations indicate that the modulation of the $\mathrm{p} 38$ MAPK signaling pathway, involving $\mathrm{I} \kappa \mathrm{B}$ and $\mathrm{NF}-\kappa \mathrm{B}$, may be one of the molecular bases for the beneficial effects of sesamin on allergic airway disease.

In summary, the present study investigated the effects of sesamin on allergen-induced airway inflammation. At the same time, the roles of $\mathrm{p} 38 \mathrm{MAPK}$ and $\mathrm{NF}-\kappa \mathrm{B}$ in this process were clarified. Following treatment of OVA-inhaled mice with sesamin, p38 MAPK phosphorylation and NF- $\kappa$ B activation was reduced. The level of Th2 cytokine airway inflammation was also attenuated. According to the results of the present study, the inhibitory effects of sesamin on OVA-induced allergic airway inflammation were partly mediated by regulating the p38 MAPK/NF- $\mathrm{BB}$ pathways. The present study also provided a crucial molecular basis for the preventive and/or therapeutic capability of sesamin for allergic airway diseases.

\section{Acknowledgements}

The present study was supported by the Natural Science Foundation of China (grant nos. 81260665 and 81160176) and the Project of Research \& Innovation of Jilin Youth Leader and Team (grant no. 20140519013JH). 


\section{References}

1. Pascual RM and Peters SP: Airway remodeling contributes to the progressive loss of lung function in asthma: an overview. J Allergy Clin Immunol 116: 477-486, 2005.

2. Kay AB: Asthma and inflammation. J Allergy Clin Immunol 87: 893-910, 1991

3. Janssen EM, van Oosterhout AJ, van Rensen AJ, van Eden W, Nijkamp FP and Wauben MH: Modulation of Th2 responses by peptide analogues in a murine model of allergic asthma: Amelioration or deterioration of the disease process depends on the Th1 or Th2 skewing characteristics of the therapeutic peptide. J Immunol 164: 580-588, 2000.

4. Mazzarella G, Bianco A, Catena E, De Palma R and Abbate GF: Th1/Th2 lymphocyte polarization in asthma. Allergy 55 (Suppl 61): S6-S9, 2000.

5. Primhak RA and Powell CV: AHR in asthma. Thorax 57: 186; author reply 186, 2002.

6. Robinson DS, Hamid Q, Ying S, Tsicopoulos A, Barkans J, Bentley AM, Corrigan C, Durham SR and Kay AB: Predominant TH2-like bronchoalveolar T-lymphocyte population in atopic asthma. N Engl J Med 326: 298-304, 1992.

7. Tournoy KG, Kips JC and Pauwels RA: Is Th1 the solution for Th2 in asthma? Clin Exp Allergy 32: 17-29, 2002.

8. Kidd P: Th1/Th2 balance: The hypothesis, its limitations, and implications for health and disease. Altern Med Rev 8: 223-246, 2003.

9. Umetsu DT, McIntire JJ, Akbari O, Macaubas C and DeKruyff RH: Asthma: An epidemic of dysregulated immunity. Nat Immunol 3: 715-720, 2002

10. Bao Z, Guan S, Cheng C, Wu S, Wong SH, Kemeny DM, Leung BP and Wong WS: A novel antiinflammatory role for andrographolide in asthma via inhibition of the nuclear factor-kappaB pathway. Am J Respir Crit Care Med 179: 657-665, 2009.

11. Janssen-Heininger YM, Poynter ME, Aesif SW, Pantano C, Ather JL, Reynaert NL, Ckless K, Anathy V, van der Velden J, Irvin CG and van der Vliet A: Nuclear factor kappaB, airway epithelium and asthma: Avenues for redox control. Proc Am Thorac Soc 6: 249-255, 2009.

12. Tully JE, Hoffman SM, Lahue KG, Nolin JD, Anathy V, Lundblad LK, Daphtary N, Aliyeva M, Black KE, Dixon AE, et al: Epithelial NF- $\kappa \mathrm{B}$ orchestrates house dust mite-induced airway inflammation, hyperresponsiveness, and fibrotic remodeling. J Immunol 191: 5811-5821, 2013.

13. Ichikawa T, Sugiura H, Koarai A, Kikuchi T, Hiramatsu M, Kawabata H, Akamatsu K, Hirano T, Nakanishi M, Matsunaga K, et al: 25-hydroxycholesterol promotes fibroblast-mediated tissue remodeling through NF- $\mathrm{KB}$ dependent pathway. Exp Cell Res 319: 1176-1186, 2013

14. Schieven GL: The biology of p38 kinase: A central role in inflammation. Curr Top Med Chem 5: 921-928, 2005.

15. Fu J, Meng X, He J and Gu J: Inhibition of inflammation by a p38 MAP kinase targeted cell permeable peptide. Med Chem 4: 597-604, 2008.

16. Saatian B, Zhao Y, He D, Georas SN, Watkins T, Spannhake EW and Natarajan V: Transcriptional regulation of lysophosphatidic acid-induced interleukin-8 expression and secretion by p38 MAPK and JNK in human bronchial epithelial cells. Biochem J 393: 657-668, 2006.

17. Saccani S, Pantano S and Natoli G: p38-Dependent marking of inflammatory genes for increased NF-kappa B recruitment. Nat Immunol 3: 69-75, 2002.

18. Woo CH, Lim JH and Kim JH: Lipopolysaccharide induces matrix metalloproteinase-9 expression via a mitochondrial reactive oxygen species-p38 kinase-activator protein-1 pathway in Raw 264.7 cells. J Immunol 173: 6973-6980, 2004.

19. Nasirullah and Latha RB: Storage stability of sunflower oil with added natural antioxidant concentrate from sesame seed oil. J Oleo Sci 58: 453-459, 2009.

20. Yokota T, Matsuzaki Y, Koyama M, Hitomi T, Kawanaka M, Enoki-Konishi M, Okuyama Y, Takayasu J, Nishino H, Nishikawa A, Osawa T and Sakai T: Sesamin, a lignan of sesame, down-regulates cyclin D1 protein expression in human tumor cells. Cancer Sci 98: 1447-1453, 2007.
21. Utsunomiya T, Shimada M, Rikimaru T, Hasegawa $\mathrm{H}$ Yamashita Y, Hamatsu T, Yamasaki M, Kaku S, Yamada K and Sugimachi K: Antioxidant and anti-inflammatory effects of a diet supplemented with sesamin on hepatic ischemia-reperfusion injury in rats. Hepatogastroenterology 50: 1609-1613, 2003.

22. Chavali SR, Zhong WW and Forse RA: Dietary alpha-linolenic acid increases TNF-alpha, and decreases IL-6, IL-10 in response to LPS: Effects of sesamin on the delta-5 desaturation of omega6 and omega3 fatty acids in mice. Prostaglandins Leukot Essent Fatty Acids 58: 185-191, 1998.

23. Iversen L, Fogh K and Kragballe K: Effect of dihomogammalinolenic acid and its 15-lipoxygenase metabolite on eicosanoid metabolism by human mononuclear leukocytes in vitro: Selective inhibition of the 5-lipoxygenase pathway. Arch Dermatol Res 284: 222-226, 1992

24. Jeng KC, Hou RC, Wang JC and Ping LI: Sesamin inhibits lipopolysaccharide-induced cytokine production by suppression of p38 mitogen-activated protein kinase and nuclear factor-kappaB. Immunol Lett 97: 101-106, 2005.

25. Phitak T, Pothacharoen P, Settakorn J, Poompimol W, Caterson B and Kongtawelert P: Chondroprotective and anti-inflammatory effects of sesamin. Phytochemistry 80: 77-88, 2012.

26. Bousquet J, Jeffery PK, Busse WW, Johnson M and Vignola AM: Asthma. From bronchoconstriction to airways inflammation and remodeling. Am J Respir Crit Care Med 161: 1720-1745, 2000 .

27. Wegmann M: Th2 cells as targets for therapeutic intervention in allergic bronchial asthma. Expert Rev Mol Diagn 9: 85-100, 2009.

28. Holt PG and Sly PD: Th2 cytokines in the asthma late-phase response. Lancet 370: 1396-1398, 2007.

29. Siebenlist U, Franzoso G and Brown K: Structure, regulation and function of NF-kappa B. Annu Rev Cell Biol 10: 405-455, 1994.

30. Baeuerle PA and Baltimore D: NF-kappa B: Ten years after. Cell 87: 13-20, 1996.

31. Baldwin AS Jr: The NF-kappa B and I kappa B proteins: New discoveries and insights. Annu Rev Immunol 14: 649-683, 1996.

32. Barnes PJ: Nuclear factor-kappa B. Int J Biochem Cell Biol 29: 867-870, 1997

33. Ray A, Siegel MD, Prefontaine KE and Ray P: Anti-inflammation: Direct physical association and functional antagonism between transcription factor NF-KB and the glucocorticoid receptor. Chest 107 (Suppl 3): S139, 1995.

34. Imanifooladi AA, Yazdani S and Nourani MR: The role of nuclear factor-kappaB in inflammatory lung disease. Inflamm Allergy Drug Targets 9: 197-205, 2010.

35. Schaeffer HJ and Weber MJ: Mitogen-activated protein kinases: Specific messages from ubiquitous messengers. Mol Cell Biol 19: 2435-2444, 1999.

36. Davis RJ: Signal transduction by the JNK group of MAP kinases. Cell 103: 239-252, 2000.

37. Han $\mathrm{J}$ and Ulevitch RJ: Emerging targets for anti-inflammatory therapy. Nat Cell Biol 1: E39-E40, 1999.

38. Kumar A, Lnu S, Malya R, Barron D, Moore J, Corry DB and Boriek AM: Mechanical stretch activates nuclear factor-kappaB, activator protein-1, and mitogen-activated protein kinases in lung parenchyma: Implications in asthma. FASEB J 17: 1800-1811, 2003.

39. Taube C, Nick JA, Siegmund B, Duez C, Takeda K, Rha YH, Park JW, Joetham A, Poch K, Dakhama A, Dinarello CA and Gelfand EW: Inhibition of early airway neutrophilia does not affect development of airway hyperresponsiveness. Am J Respir Cell Mol Biol 30: 837-843, 2004.

40. Underwood DC, Osborn RR, Kotzer CJ, Adams JL, Lee JC, Webb EF, Carpenter DC, Bochnowicz S, Thomas HC, Hay DW and Griswold DE: SB 239063, a potent p38 MAP kinase inhibitor, reduces inflammatory cytokine production, airways eosinophil infiltration, and persistence. J Pharmacol Exp The 293: 281-288, 2000.

41. Duan W, Chan JH, McKay K, Crosby JR, Choo HH, Leung BP, Karras JG and Wong WS: Inhaled p38alpha mitogen-activated protein kinase antisense oligonucleotide attenuates asthma in mice. Am J Respir Crit Care Med 171: 571-578, 2005. 